\title{
PHARMACOMETRICS
}

\section{The Influence of Variable Gastric Emptying and Intestinal Transit Rates on the Plasma Level Curve of Cimetidine; An Explanation for the Double Peak Phenomenon}

\author{
Rebecca L. Oberle ${ }^{1}$ and Gordon L. Amidon ${ }^{1,2}$
}

Received August 12, 1986-Final May 26, 1987

\begin{abstract}
A physiological flow model is presented to account for plasma level double peaks based on cyclical gastric emptying and intestinal motility in the fasted state. Central to the model is the assumption that gastric emptying and intestinal transit rates will vary directly with the strength of the contractile activity characteristic of the fasted state motility cycle. Simulated curves clearly indicate that variable gastric emptying rates can result in variable absorption rates from the gastrointestinal tract and double peaks in the plasma level curves of cimetidine. Vital to the occurrence of double peaks are (i) dosing time relative to phasic activity, (ii) variability in flow out of the stomach, and (iii) a small emptying rate constant $Q_{s} / V_{s}$, for a period of time within the first hour after administration. Variability in intestinal flow rates alone does not cause a double peak in the plasma level curve. Results of the simulations, as well as experimental results, can be categorized according to the shapes of the plasma level curves into four types: type $A, C_{p \max }(1)<C_{p \max }(2)$; type $B$, single peak; type $C, C_{p \max }(1)>C_{p \max }(2)$; type $D, C_{p \max }(1)=C_{p \max }(2)$. Assuming that the experimental results were obtained from fasted subjects, with the time of dose administration being a random variable, the frequency of the experimental curves having shape $A, B, C$, or $D$ correlates extremely well with theoretical predictions. It is conchuded that variable gastric emptying rates due to the motility cycle can account for plasma level double peaks. Furthermore, variable gastric emptying rates combined with the short plasma elimination half-life and poor gastric absorption of cimetidine can be the cause of the frequently observed plasma level double peaks.
\end{abstract}

KEY WORDS: cimetidine; oral absorption; double peaks; gastric emptying; fasted motility.

\section{INTRODUCTION}

The rate and extent of drug absorption after oral administration can be affected by the residence time of the drug in the stomach and along the intestine. In turn, the residence time is dictated to a large extent by gastric

This work was supported by the Smith Kline Beckman Corporation and the American Foundation for Pharmaceutical Education.

${ }^{1}$ College of Pharmacy, The University of Michigan, Ann Arbor, Michigan 48109-1065.

${ }^{2}$ To whom correspondence should be addressed. 
emptying and gastrointestinal motility. Because very little absorption of most drugs occurs from the stomach relative to the small intestine (1-3), drug is retained in the stomach until it is delivered to the small intestine and subsequently absorbed. For drugs with a high water solubility, dissolution is fast and is most likely not a rate-limiting factor to drug absorption. Under these circumstances, gastric emptying may be a critical determining factor in drug absorption.

Clements et al. (4) investigated the kinetics of acetaminophen with simultaneous radioisotopic measurement of gastric emptying. Results of their experiments strongly suggest gastric emptying was the rate-limiting step in the absorption of acetaminophen. Evidence of the importance of gastric emptying to drug absorption has also been provided indirectly by studying the absorption of one drug after pretreatment with a different drug that alters the rate of gastric emptying (5).

Variability in stomach emptying rates and intestinal flow rates over the course of the entire absorption process after a single dose would likely result in variable absorption rates. In this case, absorption may not be simply first-order. This could result in a somewhat complex plasma concentration-time profile. For example, double peaks in the plasma concentration-time profile were observed for acetaminophen when monoexponential emptying was interrupted by an interval of no emptying (4). Double peaks in the plasma level curve frequently occur after administration of cimetidine, an H2-receptor antagonist, as a liquid or tablet in the fasted state (6-9). Double peaks do not occur if cimetidine is administered intravenously or concomitantly with food. Other drugs known to exhibit double peaks are penicillamine, sobrerol, furosemide, prednisolone, propranolol, and aspirin (10-13, unpublished data).

The phenomenon of double peaks has often been attributed to enterohepatic recycling $(14,15)$. However, evidence for biliary excretion of cimetidine is weak since less than $1 \%$ of an $800-\mathrm{mg}$ oral dose of cimetidine was recovered in the bile (16). More recently, Wagner (10) has postulated two different absorption sites in the gastrointestinal tract for penicillamine, but the physiological basis for two absorption sites is unclear. A more physiological basis for the observed double peaks is needed. This report presents a physiological model for the gastrointestinal absorption of cimetidine and demonstrates that it can account for the observed double peak phenomenon. A subsequent publication will generalize these conclusions to drug and physiological variables that can give rise to this phenomenon.

\section{Fasted Gastrointestinal Motility}

Over the last 20 years, renewed interest in gastrointestinal (GI) motility 
has led to the recognition of its cyclical nature in the fasted state. The cycle is characterized by four phases. Phase I is a quiescent period. Phase II consists of intermittent and irregular contractions. These contractions gradually increase in strength culminating in a short period of intense contractions called Phase III, the activity phase or the housekeeper wave. Phase IV is a brief transition period from Phase III to Phase I: however, Phase IV has been found only occasionally, if at all, by some authors (17-19).

The active phase originates in the distal part of the stomach and duodenum and propagates distally through the small intestine, although not all contractions move the entire length of the small intestine (20). Therefore, the motor activity has been called the migrating motor complex (MMC). Phase III is, therefore, usually present over a definite length of the bowel at any given time. Animal and human experiments have shown the complex originates simultaneously in the stomach and duodenum $(21,22)$.

In a recent review, Sarna et al. (23) reported that Phase III starts in the stomach prior to in the duodenum but ends in the stomach and duodenum at about the same time. Approximately $20 \%$ of the time, Phase III activity starts at a more distal site such as the jejunum and migrates caudad $(24,25)$.

The mean duration of the MMC cycle in humans is in the range of 80-150 min; mean values of 149,90 , and 110 min have been observed $(22,26,27)$. The cycle duration is highly variable ranging from $15 \mathrm{~min}$ to greater than $3 \mathrm{hr}(26)$. Phases I and II last 20-90 and 10-135 min, respectively $(21,22)$. The duration of Phase III in the stomach ranges from 3 to 25 min $(23,26,28)$. Phase III lasts for approximately $3 \mathrm{~min}$ in the human duodenum $(22,26)$.

Contractions of varying intensity characteristic of the motility cycle would likely result in variable flow out of the stomach and throughout the small intestine. This is the case in the jejunum and ileum where the volumetric flow rates were 1.28 and $0.5 \mathrm{ml} / \mathrm{min}$ during Phase 111 , respectively, but were only 0.58 and $0.17 \mathrm{ml} / \mathrm{min}$ during Phases $\mathrm{I}$ and II, respectively (29). However, very little is known about the volumetric flow rates out of the stomach and duodenum as they relate to the motility cycle.

Gastric emptying of nonnutrient liquids has been reported as an apparent first-order process $(22,26)$. Hunt and MacDonald (30) found mean emptying half-lives of 9,21 , and $37 \mathrm{~min}$ for pectin meals of 330,750 , and $1250 \mathrm{ml}$, respectively. Bateman and Whittingham (31) found a mean half 1 ife for gastric emptying of a $500 \mathrm{ml}$ drink of approximately 22 min with a range of $9-40 \mathrm{~min}$. Some studies have suggested liquid emptying is not simply first-order but is variable (4). Recent studies in dogs have shown that gastric emptying of small volumes $(25-150 \mathrm{ml})$ is related to the motility pattern, but emptying of larger volumes follows first-order kinetics (32). 
Since GI motility, gastric emptying, and intestinal transit rates are variable and since most drugs are studied in the fasted state, it seems reasonable to suggest that plasma level curves may exhibit double peaks due to this variability. Therefore, a physiological flow model has been developed to account for cyclical gastric emptying and intestinal motility in the fasted state and used to estimate the influence of this variation on the plasma level time curve of cimetidine.

\section{THEORETICAL}

The GI tract is described as four serial compartments: the stomach, duodenum, jejunum, and ileum. The plasma kinetics are described by a two-compartmen: pharmacokinetic model representing the plasma from which drug is reversibly distributed and eliminated and the tissue. Figure 1 is a schematic diagram of the model. A set of six first-order linear

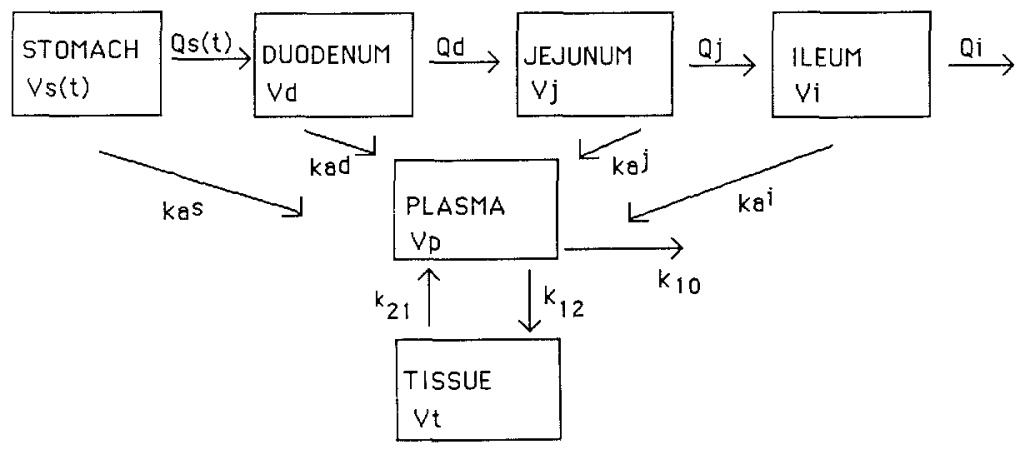

$$
\begin{aligned}
& \mathrm{dAs} / \mathrm{dt}=-(\mathrm{Qs} / \mathrm{Vs}+\mathrm{Kas}) \mathrm{As} \\
& \mathrm{dAd} / \mathrm{dt}=-(\mathrm{Qd} / \mathrm{Vd}+\mathrm{Kad}) \mathrm{Ad}+\mathrm{Qs} / \mathrm{Vs} A s \\
& d A j / d t=-(Q j / V j+K a j) A j+Q d / V d A d \\
& d A i / d t=-(Q i / V i+K a i) A i+Q j / V j A j \\
& d A p / d t=K a s A s+K a d A d+K a j A j+K a i A i+K{ }_{21} A t \\
& -\left(K_{12}+K_{10}\right) A p \\
& \mathrm{dAt} / \mathrm{dt}=\mathrm{K}_{12} \mathrm{Ap}-\mathrm{K}_{21} \mathrm{At}
\end{aligned}
$$

Fig. 1. Schematic diagram and set of differential equations describing the model. See Notation section for the meaning of the symbols. 
differential equations mathematically describes the system (Fig. 1). Initially, the dose $(300 \mathrm{mg})$ is delivered to the stomach. The initial amount is zero in all other compartments. Drug is lost from the GI compartments by flow to the nearest distal compartment or absorption into the plasma. Drug is gained in each intestinal compartment by flow from the nearest proximal compartment.

The following model assumptions are made:

1. The volumetric flow rate is directly related to the strength of the contractile activity. As a result, the flow rate increases as the cycle proceeds from Phase I to Phase III in each compartment.

2. Flow rates exiting each compartment are constant during a given phase of the motility cycle, however, vary from one phase to another.

3. Compartmental volumes are held constant.

4. The only exception to 2 and 3 above is the initial stomach exiting flow rate and volume. For the first $20 \mathrm{~min}$ after drug administration, stomach emptying is governed by an exponential decrease in stomach volume according to Eq. 1.

$$
V_{\mathrm{s}}=V_{\mathrm{s}}^{0} / e^{-\mathrm{kt}}
$$

Flow rate out of the stomach, defined as the derivative of volume with respect to time, is as follows:

$$
Q_{\mathrm{s}}(t)=-d V_{\mathrm{s}} / d t=k V_{\mathrm{s}}^{0} e^{-\mathrm{kt}}=k V_{\mathrm{s}}
$$

Therefore

$$
Q_{\mathrm{s}}(t) / V_{\mathrm{s}}(t)=k=\mathrm{a} \text { constant }
$$

A value of $0.025-0.033$ for $k$ is based on studies of liquid emptying of a $300-500 \mathrm{ml}$ test meal $(28,30,31)$. Therefore, even though stomach volume and exiting flow rate are allowed to vary with time initially, the differential equation describing drug concentration in the stomach is still first-order.

5 . The phasic activity and associated flow rates are propagated down the GI tract in agreement with available data on the migratory nature of the motility complex. Phase III is, therefore, always present somewhere in the GI tract.

6. Dissolution of the drug is not presently considered in the model. The drug is administered in solution as a bolus, and no precipitation of the drug occurs. Due to the high water solubility of cimetidine, dissolution is not expected to limit the rate of drug absorption.

7. The concentration of drug in each compartment is homogeneous throughout.

8. Gastric emptying is not altered in the model as a result of the pharmacological action of cimetidine (33). 
9. Other factors such as stomach or duodenal $p \mathrm{H}$ or osmolarity affect compartmental emptying rates minimally compared to gastrointestinal motilitý.

The time of dose administration is considered to be a random variable of uniform distribution of length equal to the mean length of the motility cycle $(105 \mathrm{~min})$. Plasma levels of the drug result from stomach emptying and subsequent absorption, distribution, and elimination. These processes are governed by parameters related to GI physiology and the properties of cimetidine. The physiological model parameters are chosen to represent the GI motility cycle in the fasted state.

\section{Physiological Parameters}

The motility cycle in the model is divided into three consecutive phases (I, II, and III) representing the physiological equivalents in the fasted state. A fourth phase corresponding to Phase IV motor activity, being relatively ill-defined and short, is not included in the model. The lengths of Phases I, II, and III used in the model can be found in Fig. 2. Model flow rates used as a function of phasic activity are illustrated in Fig. 2. The volumes of each compartment used in the model are listed in Table I. These parameters are in the range of values reported in the literature $(28,29,34,35)$.

The migratory nature of the MMC was incorporated into the model by examining available literature data on the propagation velocity of Phase III. The mean length of the gut activated simultaneously, the duration of Phase III and the lengths of each intestinal compartment $(21,22,26)$. Figure 2 also illustrates the phasic activity staggered down the GI tract as treated in the model.

\section{Parameters Related to Cimetidine}

The parameters for the iv kinetics, $K_{10}, K_{12}, K_{21}$ and $V_{\mathrm{p}}$ were obtained by fitting the intravenous data obtained by Walkenstein et al. (9) to a two-compartment model with elimination from the central compartment. The respective values of $0.0132,0.0175,0.0224 \mathrm{~min}^{-1}$, and $46147 \mathrm{ml}$ were used in the model.

Experimental rat jejunal perfusions at $1 \mathrm{mg} / \mathrm{ml}$ cimetidine concentration provided intestinal permeabilities as a function of $p \mathrm{H}$ from which absorption rate constants were calculated (unpublished data). Means and ranges of absorption rate constants for cimetidine in each GI compartment can be found in Table I. Values for $K_{\mathrm{a}}$ agree well with the reported mean pharmacokinetic value of $0.0478 \mathrm{~min}^{-1}$ (14). 


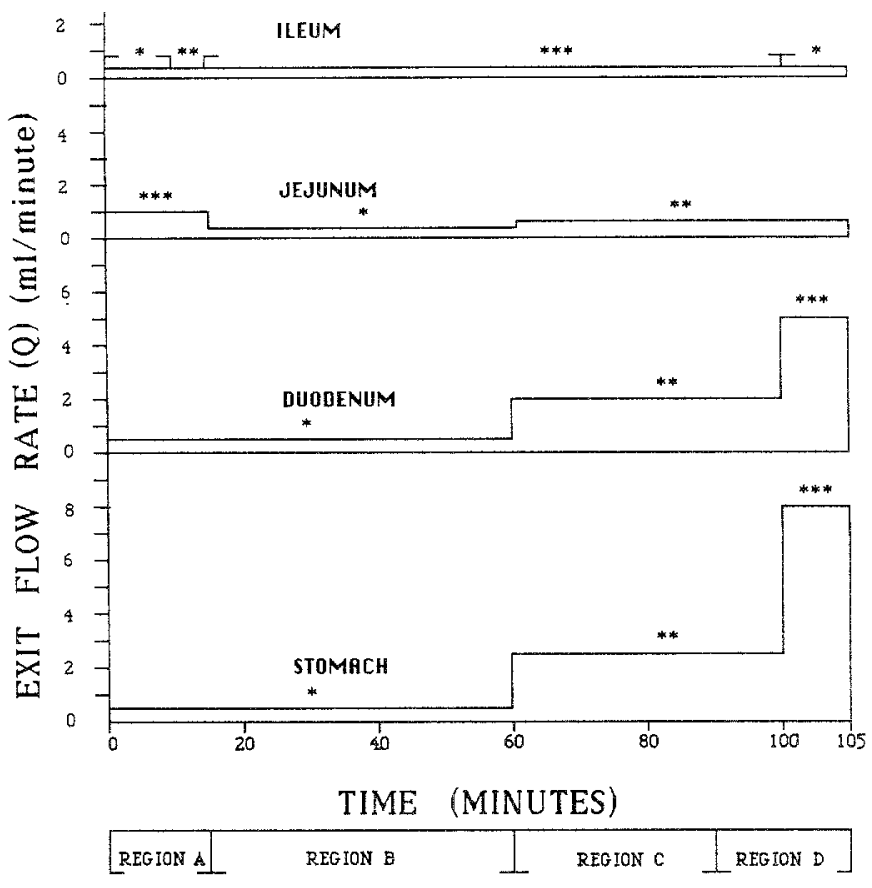

Fig. 2. Model flow rates as a function of gastrointestinal motility phase, depiction of the migrating myoelectric complex staggered down the GI tract, and illustration of defined regions $A, B, C$, and $D\left({ }^{*}\right.$-Phase I: **.Phase II: ***.Phase III).

Table I. Cimetidine Absorption Rate Constants From and Volumes of Gastrointestinal Compartments

\begin{tabular}{|c|c|c|c|c|c|c|}
\hline \multirow{2}{*}{$\begin{array}{l}\text { Physiological } \\
\text { space }\end{array}$} & \multirow{2}{*}{$\begin{array}{c}\text { Model } \\
\text { volume } \\
(\mathrm{ml})\end{array}$} & \multirow{2}{*}{$\begin{array}{l}\text { Literature } \\
\text { value }(\mathrm{ml}) \\
\text { (reference) }\end{array}$} & \multicolumn{3}{|c|}{ Experimental $K_{\mathrm{a}}\left(\mathrm{min}^{-1}\right)$} & \multirow{2}{*}{$\begin{array}{l}\text { Model } K \\
\left(\min ^{-1}\right)\end{array}$} \\
\hline & & & $p \mathrm{H}$ & Mean & Range & \\
\hline Stomach & $100^{a}$ & $\begin{array}{c}50-1500 \\
(27,34)\end{array}$ & $1-3$ & 0.00064 & $\begin{array}{l}0.0904 \\
0.00094\end{array}$ & 0.00064 \\
\hline Duodenum & 30 & $\begin{array}{l}25-75 \\
(33,34)\end{array}$ & 5.5 & 0.084 & $0.064-0.11$ & 0.07 \\
\hline Jejunum & 100 & $\begin{array}{l}50-500 \\
(33,34)\end{array}$ & 6.0 & 0.087 & $0.064-0.11$ & 0.07 \\
\hline Ileum & 100 & $\begin{array}{c}50-500 \\
(33,34)\end{array}$ & $\begin{array}{l}6.0 \\
7.0\end{array}$ & $\begin{array}{l}0.035 \\
0.111\end{array}$ & $\begin{array}{l}0.026-0.044 \\
0.074-0.180\end{array}$ & 0.06 \\
\hline Plasma & 46,147 & $\begin{array}{c}17,762-54,112 \\
(9)\end{array}$ & - & - & - & - \\
\hline
\end{tabular}

${ }^{a} V_{\mathrm{s}}=100 \mathrm{ml}$ after initial volumetric emptying period of $20 \mathrm{~min}$. 


\section{METHOD OF SOLUTION}

The differential equations describing the model system can be written in matrix form

$$
x^{\prime}=\mathrm{A} x
$$

where $x$ is the vector of amounts in the various compartments and A the coefficient matrix.

Analytical solutions are obtained using eigenvalue theory with the aid of an IBM-AT computer and the IMSL math/PC library of subroutines. FORTRAN programs were written to simulate concentration-time profiles for each compartment, the absorption rate from each GI compartment, the gastric emptying rate, the fraction of dose absorbed from each GI compartment, and the fraction of dose emptied from the stomach versus time. The absorption rate or input of drug into the plasma from the GI tract is equal to

$$
I(t)=K_{\mathrm{as}}\left(A_{\mathrm{s}}\right)+K_{\mathrm{ad}}\left(A_{\mathrm{d}}\right)+K_{\mathrm{aj}}\left(A_{\mathrm{j}}\right)+K_{\mathrm{ai}}\left(A_{\mathrm{i}}\right)
$$

The amounts of the dose absorbed from the stomach, duodenum, jejunum, ileum, and combined compartments versus time $(t)$ were determined by integrating numerically the appropriate terms from 0 to $t$ using the trapezoidal rule. The emptying rate of drug from the stomach is equal to

$$
d M / d t(s-d)=D E R=Q_{\mathrm{s}} / V_{\mathrm{s}}\left(A_{\mathrm{s}}\right)
$$

\section{RESULTS AND DISCUSSION}

The effect of time of dose aministration relative to fasted state phasic activity was studied by administering the drug at every minute in a theoretical motility cycle (i.e., at the beginning of Phase I, 1 min into Phase I, etc.). Simulations of the plasma drug concentration-time profiles showing this effect can be found in Fig. 3.

The simulated plasma level time curves clearly indicate that double peaks can occur as a result of variable gastric emptying. The plasma level curve is defined mathematically as having double peaks if the curve exhibits two maximas. Whether or not a double peak occurs in the plasma level curve is highly dependent on the flow rate out of the stomach after dosing and the time of dose administration relative to the MMC cycle. As a result of these simulations, four regions have been defined based on the shape of the predicted plasma level profiles (Fig. 2). Type $\mathrm{A}\left[C_{\mathrm{p} \max }(1)<C_{\mathrm{p} \max }(2)\right]$ occurs when the drug is administered during the first $15 \mathrm{~min}$ of Phase I activity in the stomach. Type $B$ (single peak) occurs when the drug is administered anywhere from $15 \mathrm{~min}$ into Phase I to the beginning of Phase 


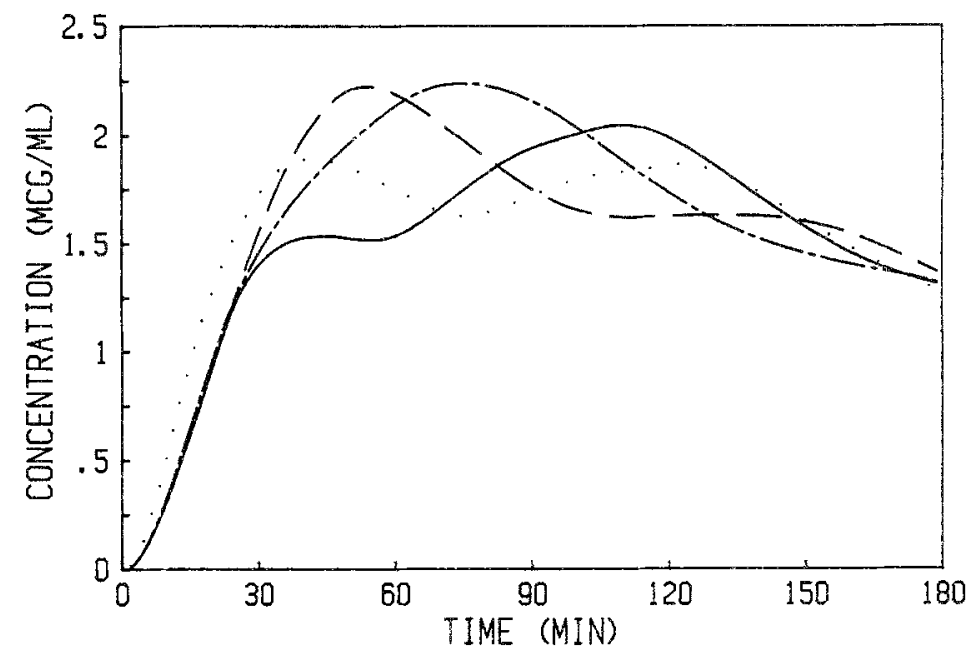

Fig. 3. Illustration of mean plasma concentration time profiles of cimetidine when drug is dosed in region A (-), region B (- - ), region $\mathrm{C}(--)$ and region $D(\ldots .$.$) (see Fig. 2).$

II, 60 min (15-60 min). Type C $\left[C_{\mathrm{pmax}}(1)>C_{\mathrm{pmax}}(2)\right]$ occurs when the drug is administered from the beginning of Phase II to $30 \mathrm{~min}$ into Phase II $(60-90)$. Type $\mathrm{D}\left[C_{\mathrm{pmax}}(1)=C_{\mathrm{pmax}}(2)\right]$ occurs when the drug is administered close to or in conjunction with the MMC in the stomach, and includes the remainder of the motility cycle $(90-105 \mathrm{~min})$.

If the drug is dosed in region $\mathrm{A}$, the average plasma profile exhibits double peaks where $C_{\text {pmax }}(1)$ is less than $C_{\text {pmax }}$ (2) (Fig. 3). After an initial volumetric emptying period of $20 \mathrm{~min}$, the rate of gastric emptying becomes relatively slow due to the quiescent phase. As a result, the drug is retained in the stomach and drug concentrations in the intestine and plasma fall. At the beginning of Phase II, approximately $50 \%$ of the dose remains in the stomach (Fig. 4). Therefore, an increased flow rate at 45-60 min results in an increase in absorption substantial enough to cause a double peak. The predicted probability of a plasma level curve exhibiting this shape was estimated by dividing the number of simulations showing this shape by the total number of simulations $(15 / 105=14 \%)$.

In contrast, if the drug is administered in region $B$, the plasma level curve exhibits only a single peak (Fig. 3 ). The concentration of drug in the intestinal compartments also approaches a single peak. As the drug is administered later in gastric Phase I activity, the duration of the quiescent period after initial volumetric emptying decreases and plasma levels do not fall as a result of slower emptying. The concentration of drug in the plasma does not peak until $60 \mathrm{~min}$ at which time approximately $75 \%$ of the dose 


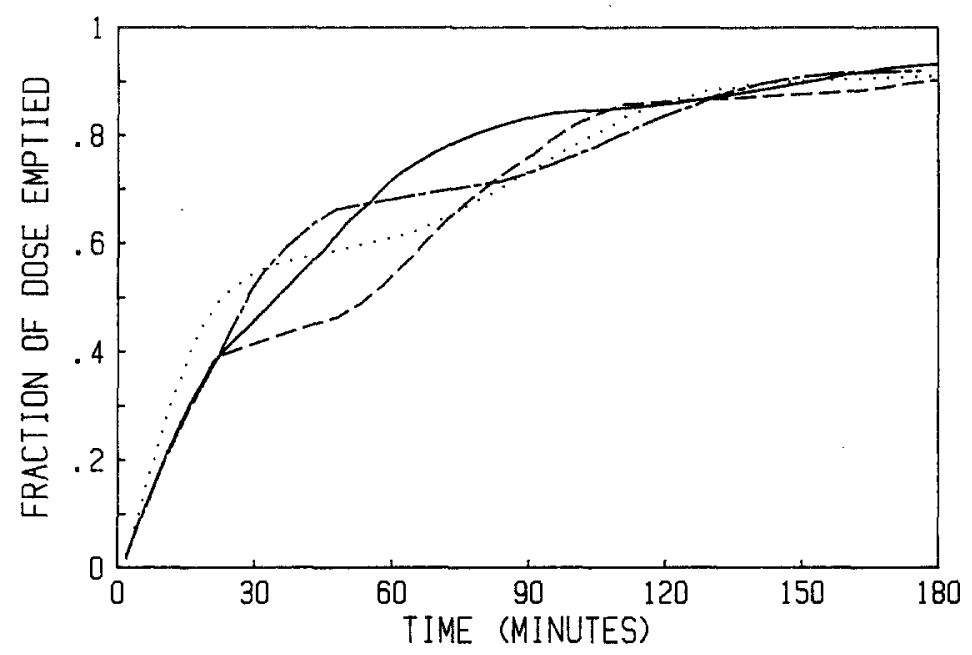

Fig. 4. Fraction of dose emptied from the stomach vs. time: (- - ) region $\mathrm{A}$; $(\longrightarrow)$ region $\mathrm{B} ;(--$,$) region \mathrm{C} ;(\ldots)$ region $\mathrm{D}$.

has already left the stomach (see Fig. 4). The next increase in $Q_{\mathrm{s}}$ occurs at 105-150 min after dosing, but has little impact on the plasma level curve since most of the dose has already emptied the stomach. The predicted probability of a plasma level curve showing only a single peak is approximately $43 \%$.

In contrast to region $\mathrm{A}$, dosing in region $\mathrm{C}$ occurs closer to Phase III in the stomach. Therefore $C_{\text {pmax }}(1)$ is greater than $C_{\text {pmax }}(2)$ (Fig. 3). However, a second peak is possible because Phase I activity commences within a short time after dosing and lasts long enough to allow for a sufficient delay in stomach emptying of the drug. The predicted probability of this curve shape is approximately $29 \%$.

If the drug is administered in region $\mathrm{D}$, double peaks of approximately equal magnitude occur (Fig. 3). In this case, an MMC occurs coincident with dosing. Approximately $14 \%$ of the simulated plasma level curves showed this type of a profile. The average of all simulations indicates that the mean plasma level curve will tend to exhibit only a single peak.

The effect of dosing time relative to phasic activity is notable in the curves for the first several hours after which time no real differences between them are apparent. Plasma levels are relatively insensitive to variability in gastric emptying rates and intestinal flow rates after $120 \mathrm{~min}$ because approximately $85 \%$ of the dose has already been absorbed.

If the flow rates exiting the intestinal compartments are varied, but the flow rate out of the stomach is held constant, the simulated plasma level curves do not exhibit double peaks. Since the absorption rate constants in 


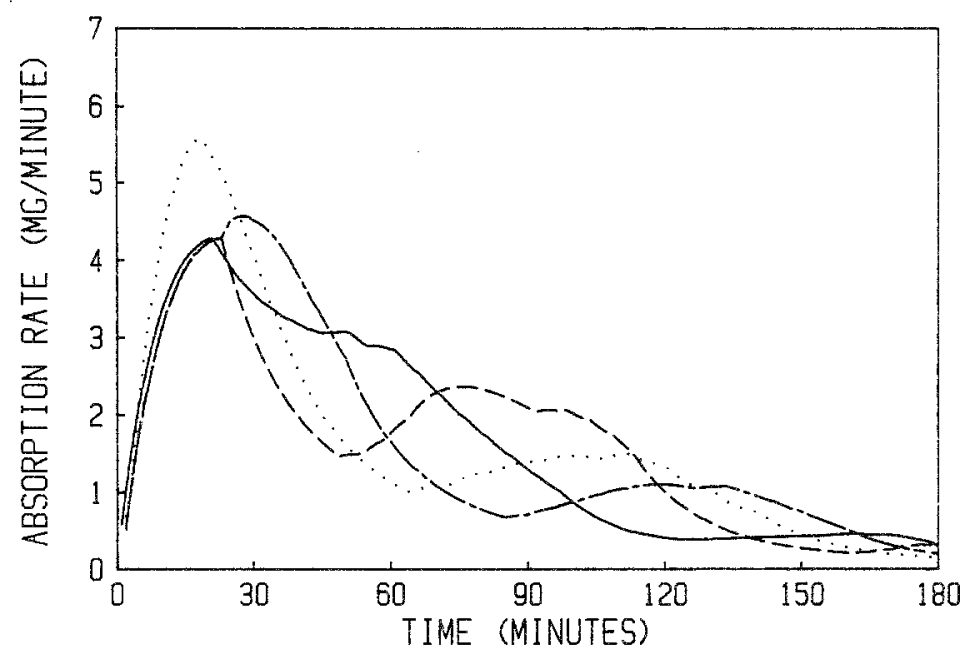

Fig. 5. Absorption rate of drug from the gastrointestinal tract vs. time: (- -$)$ region $\mathrm{A} ;(-)$ region $\mathrm{B} ;(\ldots--)$ region $\mathrm{C} ;(\ldots)$ region $\mathrm{D}$.

the intestinal compartments are not drastically different from each other, the variability of the residence time in each intestinal compartment does not result in substantial variability in the overall absorption rate.

In general, however, some drugs may be absorbed at different rates from each intestinal location. Some examples may be weak electrolytes with $p \mathrm{~K}_{\mathrm{a}}$ 's in the range of intestinal $p \mathrm{H}$ or nonpassively absorbed drugs. Variable flow through the small intestine may contribute to variable absorption rate and plasma level profiles of these drugs. Therefore, a general model containing separate intestinal compartments may be necessary for other drugs.

Figures 4 and 5 simulate the fraction of dose emptied, and absorption rate versus time, respectively, corresponding to the plasma level curves discussed above. Double peaks in the overall absorption rate profile correlate well with double peaks in the plasma level curves. Emptying patterns of the drug from the stomach also correlate closely with plasma level curves. The model suggests that gastric emptying is a major factor controlling initial plasma levels of cimetidine.

\section{Frequency of Double Peaks; Comparison of Simulated and Observed Results}

Simulated data were compared to the results obtained by Walkenstein et al. (9) and Berardi et al. (36, personal communication). The blood level curves after oral administration of cimetidine exhibited double peaks in approximately $50-75 \%$ of the subjects studied. Approximately $57 \%$ of the theoretical curves discussed above exhibited double peaks. 
The shapes of the experimental individual plasma level profiles were categorized similar to simulated data as four types. The profile is type $\mathrm{A}$, $\mathrm{C}$, or D if $C_{\mathrm{pmax}}(1)$ is less than $C_{\mathrm{pmax}}(2)$, greater than $C_{\mathrm{pmax}}(2)$ or approximately equal to $C_{\mathrm{pmax}}(2)$, respectively. Type $\mathrm{B}$ is defined as only a single peak.

This model differs from other models in its capacity to predict the frequency of double peaks expected. The probabilities predicted by the model are based on available physiological data (i.e., lengths of the fasted state motility phases, flow rates, etc.) and pharmacokinetic data of cimetidine (elimination rate, absorption rate, etc.). The model predicts 14.3 , $42.8,28.6$, and $14.3 \%$ of all curves should have shape A, B, C, and D, respectively. Given the fact that cimetidine would have been administered to fasted subjects at a random time in their motility cycles during a pharmacokinetic study, we would expect the percentages of experimental curves having shape $\mathrm{A}, \mathrm{B}, \mathrm{C}$, or $\mathrm{D}$ to correlate with theoretical predictions if variable gastric emptying due to the motility cycle is responsible for the double peaks.

The predicted frequency of double peaks and the shapes of the plasma level curves correlate extremely well with experimental results from three separate studies (Fig. 6) (9, 36, personal communication). This agreement supports the hypothesis that double peaks are a result of variable and

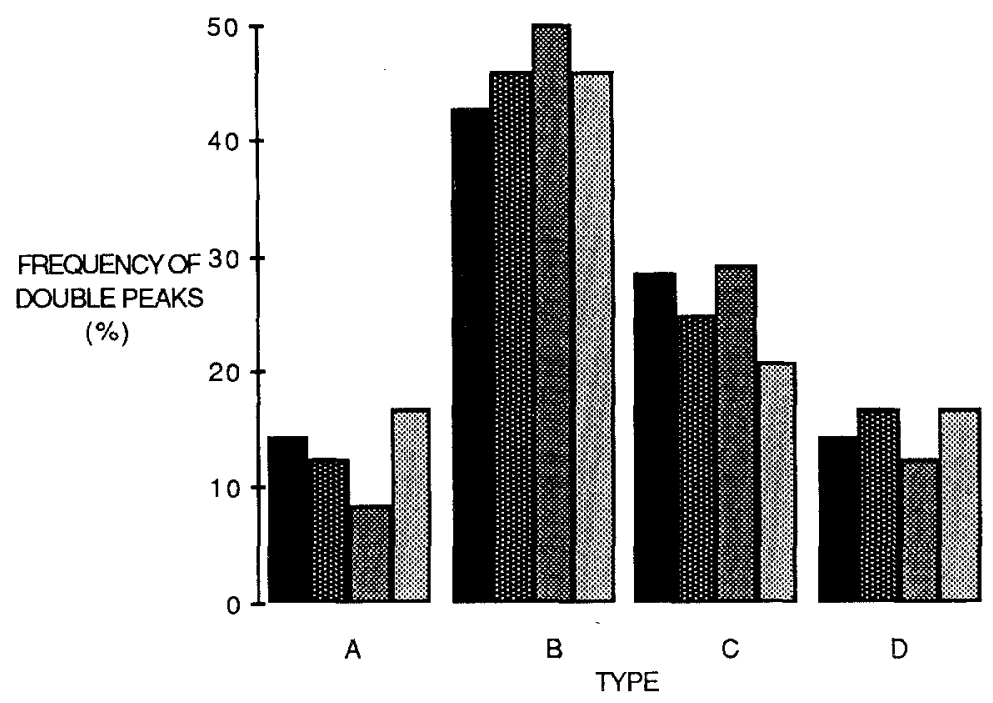

Fig. 6. Frequency of double peaks: theoretical vs. experimental. (1st bar) theoretical; (2nd bar) Walkenstein et al. (9); (3rd bar) Berardi-study A (personal communication); (4th bar) Berardi-study B (personal communication). 
delayed emptying of the drug from the stomach associated with the motility cycle.

\section{Effect of Motility Cycle and Phase Length}

The length of the motility cycle, Phases $\mathbf{i}, \mathrm{II}$, and III were reasonably altered to investigate their influence on the plasma drug level curves and frequency of double peaks. The duration of each phase influences the predicted frequency of double peaks (Fig. 7). If the duration of Phase $I$ is long relative to Phase II, the probability of the plasma level curve exhibiting double peaks is higher than if the duration of Phases $I$ and $I I$ is equal. Conversely, if Phase II is longer than Phase I, the probability of double peaks is slightly less than if the duration of Phases I and II is equal. Since $20 \%$ of all MMCs do not include an antral component $(24,25)$, this situation was simulated by only including Phases $I$ and II in the stomach for all simulations. In this extreme case, the model predicts double peaks will occur more often, approximately $67 \%$ of the time. Increasing the flow rate exiting the stomach $(q s)$ or decreasing the volume of the stomach ( $v s$ ) will reduce the predicted frequency of double peaks.

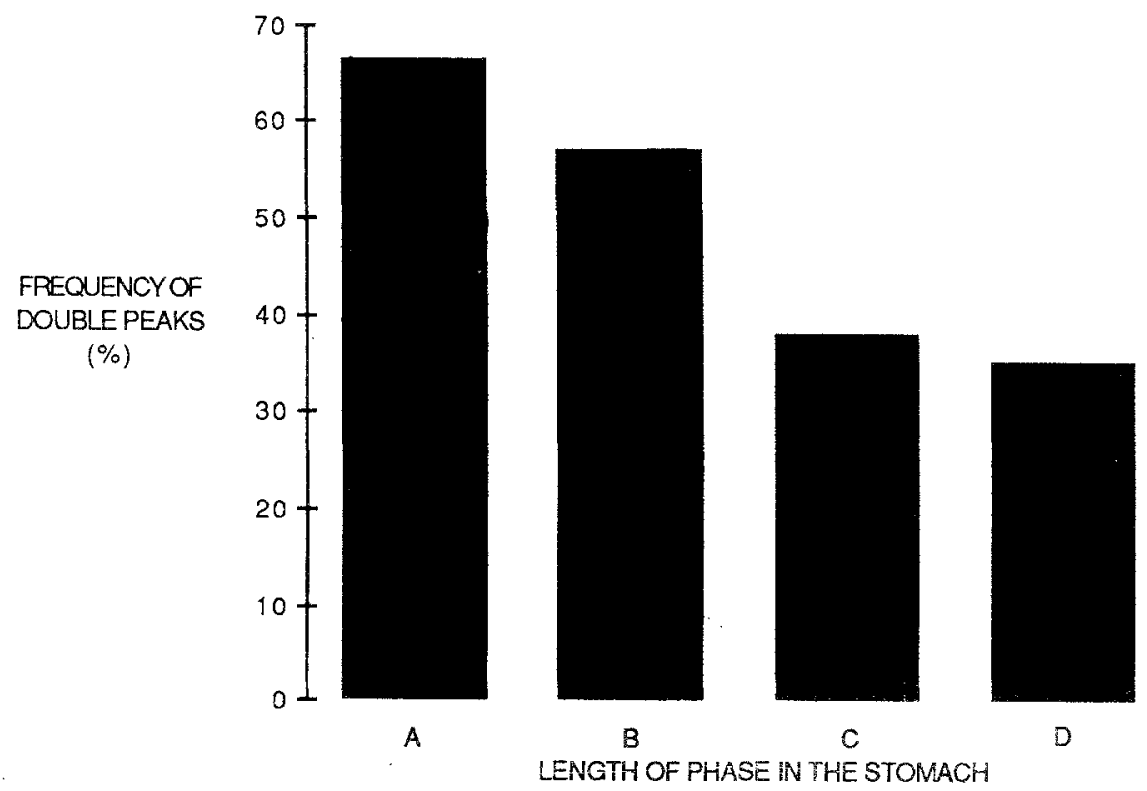

Fig. 7. The effect of motility phase length on the predicted frequency of double peaks. (A), Phase I-60 min, Phase II-40 min, Phase III $-0 \mathrm{~min}$; (B), Phase I-60 min, Phase II $-40 \mathrm{~min}$, Phase III-5 min; (C), Phase I-40 min, Phase II-40 min, Phase III-5 min; (D), Phase 1.60 min, Phase II-80 min, Phase $11 \mathrm{I}-5 \mathrm{~min}$. 


\section{Sampling Considerations}

The sampling scheme of the experimental data cited above included time points of $0,15,30,45,60,90,120,180,240$, and $360 \mathrm{~min}$. The sampling times could alter the observed frequency of double peaks. However, if only the predicted plasma levels at times comparable to a typical sampling scheme were used, the percentages of theoretical curves having shapes A, B, C, and D were not altered significantly.

\section{SUMMARY}

The simulations suggest that the MMC and associated variability in stomach emptying rates can result in double peaks in the plasma level curve of cimetidine. The following physiological factors are important with respect to the appearance of double peaks in and the shapes of the plasma level curves: (i) the dosing time relative to phasic activity; (ii) variability in emptying rates after dosing; (iii) the length of each motility phase, particularly the quiescent period, after dosing; and (iv) the stomach emptying rates as a function of phasic activity.

Since the model is based on a physiological cycle, it is possible to predict the frequency of double peaks. The frequency of theoreticai curve types A, B, C, and D correlates extremely well with experimental data indicating that variability in gastric emptying rates associated with the fasted state motility cycle is a plausible explanation for the double peak phenomenon. This explanation for observed plasma level double peaks provides an alternative to enterohepatic recycling or two-site absorption.

The capacity of the model to predict frequency is something other models have been unable to do. Because of this capacity, the legitimacy of the motility cycle as a cause of double peaks can be tested with already available experimental plasma level data. Human studies are being conducted to further test the validity of and refine the current model.

\section{NOTATION}

$A_{\mathrm{s}} \quad$ Amount of drug in the stomach

$A_{\mathrm{d}} \quad$ Amount of drug in the duodenum

$A_{\mathrm{j}} \quad$ Amount of drug in the jejunum

$A_{\mathrm{i}} \quad$ Amount of drug in the ileum

$A_{\mathrm{p}} \quad$ Amount of drug in the plasma

$A_{\mathrm{t}} \quad$ Amount of drug in the peripheral compartment

$Q_{\mathrm{s}} \quad$ Flow rate exiting the stomach

$Q_{\mathrm{d}} \quad$ Flow rate exiting the duodenum

$Q_{j} \quad$ Flow rate exiting the jejunum

$Q_{\mathrm{i}} \quad$ Flow rate exiting the ileum

$V_{\mathrm{s}} \quad$ Volume of stomach contents 


$\begin{array}{ll}V_{\mathrm{d}} & \text { Volume of duodenal contents } \\ V_{\mathrm{j}} & \text { Volume of jejunal contents } \\ V_{\mathrm{i}} & \text { Volume of ileal contents } \\ V_{\mathrm{p}} & \text { Volume of distribution } \\ V_{\mathrm{s}}^{0} & \text { Initial volume of stomach contents } \\ K_{\mathrm{as}} & \text { Absorption rate constant of cimetidine from the stomach } \\ K_{\mathrm{ad}} & \text { Absorption rate constant of cimetidine from the duodenum } \\ K_{\mathrm{aj}} & \text { Absorption rate constant of cimetidine from the jejunum } \\ K_{\mathrm{ai}} & \text { Absorption rate constant of cimetidine from the ileum } \\ K_{12} & \text { Distribution rate constant of cimetidine from plasma to tissue } \\ K_{21} & \text { Distribution rate constant of cimetidine from tissue to plasma } \\ K_{10} & \text { Elimination rate constant of cimetidine from the plasma } \\ I & \text { Input of drug into the plasma from the gastrointestinal tract } \\ D E R & \text { Emptying rate of the drug from the stomach into the duodenum } \\ C_{\mathrm{pmax}}(1) & \text { First maximum drug concentration in the plasma } \\ C_{\mathrm{pmax}}(2) & \text { Second maximum drug concentration in the plasma } \\ t_{\mathrm{max}}(1) & \text { Time of first maximum drug concentration in the plasma } \\ t_{\mathrm{max}}(2) & \text { Time of second maximum drug concentration in the plasma }\end{array}$

\section{REFERENCES}

1. R. C. Heading, J. Nimmo, L. F. Prescott, and P. Tothill. The dependence of paracetamol absorption on the rate of gastric emptying. Br. J. Pharmacol. 47:415-421 (1973).

2. R. R. Levine. Factors affecting gastrointestinal absorption of drugs. Dig. Dis. 15:171-188 (1970)

3. W. S. Nimmo, R. C. Heading, J. Wilson, P. Tothill, and L. F. Prescott. Inhibition of gastric emptying and drug absorption by narcotic analgesics. Br. J. Clin. Pharmacol. 2:509-513 (1975).

4. J. A. Clements, R. C. Heading, W. S. Nimmo, and L. F. Prescott. Kinetics of acetaminophen absorption and gastric emptying in man. Clin. Pharmacol. Ther. 24:420-431 (1978).

5. W. S. Nimmo. Drugs, disease, and altered gastric emptying. Clin. Pharmacokin. 1:189-203 (1976).

6. A. Grahnen, C. von Bahr, B. Lindstrom, and A. Rosen. Bioavailability and pharmacokinetics of cimetidine. Eur. J. Clin. Pharmacol. 16:335-340 (1979).

7. J. Webster, H. E. Barber, G. M. Hawksworth, T. A. Jeffers, J. Peterson, J. C. Petrie, P. W. Brunt, N. A. G. Mowat, and R. Griffiths. Cimetidine-a clinical and pharmacokinetic study. Br. J. Clin. Pharmacol. 11: 333-338 (1981).

8. G. Bodemar, B. Norlander, L. Fransson, and A. Walan. The absorption of cimetidine before and during maintenance treatment with cimetidine and the influence of a meal on the absorption of cimetidine: studies in patients with peptic ulcer. Br. J. Clin. Pharmacol. 7:23-31 (1979).

9. S. S. Walkenstein, J. W. Dubb, W. C. Randolph, W. J. Westlake, R. M. State, and A. P. Intoccia. Bioavailability of cimetidine in man. Gastroenterology 74:360-365 (1978).

10. J. G. Wagner. Unusual pharmacokinetics. In L. Z. Benet, G. Levy, and B. L. Ferraiolo (eds.), Pharmacokinetics-A Madern View, Plenum Press, New York, 1984, pp. 173-189.

11. U. Shukla. The pharmacokinetics of sobrerol in normal human volunteers. Ph.D. Dissertation, University of Michigan, 1985, pp. 115-117.

12. M. M. Hammarlund, L. K. Paalzow, and B. Odlind. Pharmacokinetics of furosemide in man after intravenous and oral administration: application of moment analysis. Eur. $J$. Clin. Pharmacol. 26:197-207 (1984). 
13. C. Y. Lui, R. Oberle, D. Fleisher, and G. L. Amidon. A radiotelemetric method for evaluation of enteric coating performance: comparison of enteric coated and plain aspirin tablets. J. Pharm. Sci. 75:469-474 (1986).

14. P. Veng-Pedersen. Pharmacokinetics and bioavailability of cimetidine in humans. J. Pharm. Sci. 69:394-398 (1980).

15. P. Veng-Pedersen. Pharmacokinetic analysis of linear system approach I: Cimetidine bioavailability and second peak phenomenon. J. Pharm. Sci. 70:32-38 (1981).

16. R. W. Spence, L. R. Celestin, R. De La Guardia, C. A. MacMullen, and D. A. McCormick. Biliary secretion of cimetidine in man. In Proceedings of the 2nd International Symposium on Histamine H2-Receptor Antagonists, Excerpta Medica, Amsterdam, The Netherlands, 1977 , p. 81 .

17. C. F. Code and J. A. Marlett. The interdigestive myoelectric complex of the stomach and small bowel of dogs. J. Physiol. 246:289-309 (1975).

18. M. L. Grivel and Y. Ruckebusch. The propagation of segmental contraction along the small intestine. J. Physiol. 227:611-625 (1972).

19. L. Bueno, J. Fioramonti, and Y. Ruckebusch. Rate of flow of digesta and electrical activity of the small intestine in dogs and sheep. J. Physiol. 249:69-85 (1975).

20. J. E. Kellow, T. J. Borody, S. F. Phillips, R. L. Tucker, and A. C. Haddad. Human interdigestive motility: variations in patterns from esophagus to colon. Gastroenterology 91:386-395 (1986).

21. C. F. Code and J. Schlegel. The gastrointestinal interdigestive housekeeper: motor correlates of the interdigestive myoelectric complex of the dog. In E. E. Daniel (ed)., Proceedings of the Fourth International Symposium of GI Motility, Mitchell Press, Vancouver, 1973, pp. 631-634.

22. P. Fleckenstein. Migrating electrical spike activity in the fasting human small intestine. Dig. Dis. 23:769-775 (1978).

23. S. K. Sarna, H. V. Ammon, L. G. Walter, and R. P. Ryan. Relationship between different phases of MMC and transit time: A reappraisal. Gastroenterology 88:1570 (1985).

24. S. K. Sarna. Cyclic motor activity; migrating motor complex: 1985. Gastroenterology 89:894-913 (1985).

25. C. P. Dooley, D. Mello, and J. E. Valenzuela. Effects of aspirin and prostaglandin E2 on interdigestive motility complex and duodenal reflux in man. Dig. Dis. Sci. 30:513-521 (1985).

26. P. Kerlin and S. Phillips. Variability of motility of the ileum and jejunum in healthy humans. Gastroenterology 82:694-700 (1982).

27. P. Fleckenstein and A. Oigaard. Electrical spike activity in the human small intestine; a multiple electrode study of fasting diurnal variations Dig. Dis. 23:776-780 (1978).

28. H. W. Davenport. Physiology of the Digestive Tract, 2nd ed., Year Book Medical Publishers Inc., Chicago, 1966, p. 44.

29. P. Kerlin, A. Zinsmeister, and S. Phillips. Relationship of motility to flow of contents in the human small intestine. Gastroenterology 82:701-706 (1982).

30. J. N. Hunt and I. MacDonald. The influence of volume on gastric emptying. J. Physiol. 126:459-474 (1954).

31. D. N. Bateman and T. A. Whittingham. Measurement of gastric emptying by real-time ultrasound. Gut 23:524-527 (1982).

32. P. K. Gupta, A. Rubinstein, and J. R. Robinson. Gastric emptying of liquids in fasted dog. (abstract) Pharm. Res. 3:74S (1986).

33. R. F. A. Logan, J. A. H. Forrest, G. P. McLoughlin, G. Lidgard, and R. C. Heading. Effect of cimetidine on serum gastrin and gastric emptying in man. Digestion 18:220-226 (1978).

34. L. R. Johnson ed. Physiology of the Digestive Tract, 2nd ed., Raven Press, New York, 1981, pp. 906-912.

35. D. N. Granger, J. A. Barrowman, and P. R. Kvietys. Clinical Gastrointestinal Physiology, W. B. Saunders, Philadelphia, 1985, pp. 105-108.

36. R. R. Berardi, I. A. Cohen, M. L. Hyneck, G. F. Lockwood, U. A. Shukla, E. Sakmar, J. J. Wells, and J. G. Wagner. Comparative bioavailability study of two tablet formulations of cimetidine. Biopharm. Drug Dispos. 5:169-176 (1984). 